\title{
Prostaglandin E-EP4-Mediated Fibulin-1 Up-regulation Plays a Role in Intimal Thickening of the Ductus Arteriosus
}

\author{
Satoko Ito, Utako Yokoyama, Junichi Saito, \\ Munetaka Masuda, Toshihide Asou, \\ and Yoshihiro Ishikawa
}

\author{
Keywords \\ Ductus arteriosus $\cdot$ Cell migration $\cdot$ Intimal thickening
}

The normal closure of the ductus arteriosus (DA) consists of two steps: vasoconstriction and intimal thickening (IT). We have revealed that prostaglandin E2 $\left(\mathrm{PGE}_{2}\right)$-EP4 signaling plays a critical role in IT formation via smooth muscle cell (SMC) migration through hyaluronic acid [1]. In this study, we found that fibulin-1 was the most significantly up-regulated gene by EP4 stimulation in DA smooth muscle cells (SMCs).

It has been reported that fibulin-1 has binding domains for ADAMTS-1 (a disintegrin and metalloprotease with thrombospondin motif type 1) and versican [2, 3], which participates in cell migration, and this fibulin-1-binding protease ADAMTS-1 promotes versican fragmentation $[4,5]$. Furthermore, coupling of fragmented versican and hyaluronic acid promotes cell migration [6]. We speculated that fibulin-1 promotes DASMC migration and induces IT of the DA with ADAMTS-1 and versican. We aimed to examine the role of $\mathrm{PGE}_{2}-\mathrm{EP} 4$-signaling-mediated fibulin-1in IT of the DA.

S. Ito $\cdot$ U. Yokoyama $(\bowtie) \cdot$ J. Saito $\cdot$ Y. Ishikawa

Cardiovascular Research Institute, Yokohama City University, Yokohama, Japan

e-mail: utako@yokohama-cu.ac.jp

M. Masuda

Department of Surgery, Yokohama City University, Yokohama, Japan

T. Asou

Department of Cardiovascular Surgery, Kanagawa Children's Medical Center,

Yokohama, Japan 
Based on the microarray analysis showing that fibulin- 1 was the most increased gene by EP4 stimulation in DASMCs, we performed RT-PCR and confirmed similar findings. EP4 stimulation did not increase fibulin-1 in aortic SMCs. Protein expression of fibulin-1 was markedly increased by EP4 stimulation in DASMCs. Immunohistochemistry of rat DA tissues showed that fibulin-1, ADAMTS-1, and fragmented versican were co-localized in the area of IT. VersicanV1 mRNA expression was significantly higher in endothelial cells than in DASMCs, and ADAMTS-1 was expressed in both endothelial cells and DASMCs. EP4 stimulation significantly increased binding of hyaluronic acid to fragmented versicanV1 protein in DASMCs. A Scratch assay showed that EP4 promoted DASMC migration, which was attenuated by fibulin-1-targeted siRNA and ADAMTS-1-targeted siRNA.

In conclusion, $\mathrm{PGE}_{2}$-EP4-mediated fibulin-1 integrates extracellular matrices such as ADAMTS-1, versican V1, and hyaluronic acid to promote SMC migration of the DA.

Acknowledgment This study was funded by MEXT/JSPS KAKENHI (SI, 43008732; U.Y., 16H05358, 15H05761; J.S., 16H07107; Y.I., H1605300, 16K15205), Yokohama Foundation for Advancement of Medical Science (J.S.), and the Japan Agency for Medical Research and Development (AMED) (Y.I., 66890011, 66890023, 17ek0109240h0001, A261TS).

\section{References}

1. Yokoyama U, et al. Chronic activation of the prostaglandin receptor EP4 promotes hyaluronanmediated neointimal formation in the ductus arteriosus. J Clin Invest. 2006;116:3026-34.

2. Argraves WC. Fibulin, a novel protein that interacts with the fibronectin receptor beta subunit cytoplasmic domain. Cell. 1989;58(4):623-9.

3. Lee NV. Fibulin-1 acts as a cofactor for the matrix metalloprotease ADAMTS-1. J Biol Chem. 2015;280(41):34796-804.

4. Jonsson-Rylander AC, et al. Role of ADAMTS-1 in atherosclerosis; remodeling of carotid artery, immunohistochemistry, and proteolysis of versican. Thromb Vasc Biol. 2005;25(10):2075-80.

5. Nandadasa $\mathrm{S}$, et al. The multiple, complex roles of versican and its proteolytic turnover by ADAMTS proteases during embryogenesis. Matrix Biol. 2014;35:34-41.

6. Wight TN. Provisional matrix: arole for versican and hyaluronan. Matrix Biol. 2017;60-61:38-56.

Open Access This chapter is licensed under the terms of the Creative Commons Attribution 4.0 International License (http://creativecommons.org/licenses/by/4.0/), which permits use, sharing, adaptation, distribution and reproduction in any medium or format, as long as you give appropriate credit to the original author(s) and the source, provide a link to the Creative Commons license and indicate if changes were made.

The images or other third party material in this chapter are included in the chapter's Creative Commons license, unless indicated otherwise in a credit line to the material. If material is not included in the chapter's Creative Commons license and your intended use is not permitted by statutory regulation or exceeds the permitted use, you will need to obtain permission directly from the copyright holder.

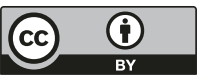

